\title{
A EFICIÊNCIA MASTIGATÓRIA É ALTERADA PELA MALOCLUSÃO?
}

Alfonso SÁNCHEZ-AYALA, Ana Paula GEBERT, Eloisa De Paula GODOY, Gislaine MARTINS, Osnara Maria Mongruel GOMES

O objetivo deste estudo foi avaliar a eficiência mastigatória de sujeitos com maloclusão. Foram utilizados 64 sujeitos saudáveis, de 15 a 50 anos de idade, e com diagnostico clinico de maloclusão classe I, classe II-1, classe II-2 e classe III $(n=16)$. Um grupo diagnosticado com normoclusão $(n=16)$ foi utilizado como controle. A eficiência mastigatória foi analisada através da avaliação do rendimento mastigatório (por meio da mastigação de alimento teste mastigável artificial até 20 ciclos e análise de peneirado) e habilidade mastigatória (por meio de um questionário de auto-percepção). Foi também avaliado o índice de massa corpórea. $\mathrm{O}$ rendimento mastigatório foi significativamente maior no grupo com maloclusão classe III (tamanho mediano de partícula triturada $X_{50}=4.29 \mathrm{~mm}$ ), o qual foi significativamente diferente ao grupo com maloclusão classe II-2 $\left(X_{50}=3.20 \mathrm{~mm}\right)$ e normoclusão $\left(X_{50}=3.40 \mathrm{~mm}\right)$. Os sujeitos com rendimento mastigatório diminuído e maloclusão classe III apresentaram maior tempo mastigatório que o grupo controle. A habilidade mastigatória também mostrou diferencias significativas entre as maloclusões, porém estas não foram significativas. O índice de massa corpóreo foi significativamente maior no grupo com maloclusão classe III quando foi comparado com o grupo com maloclusão classe II-1. A eficiência mastigatória é alterada pela maloclusão. 